\title{
Acceptance of Testing for Genetic Predisposition to Breast Cancer: The Attitude of Medical Professionals
}

\author{
E. Simeonov, S. Shopova and B. Dimitrov \\ Section of Clinical Genetics, Department of \\ Pediatrics, Medical Faculty, District \\ Oncology Clinic, Sofia, Bulgaria
}

Background: Late diagnosis in more than $60 \%$ of cases of breast cancer and absence of cancer genetics services characterize the present situation in Bulgaria. This study was undertaken in the recently set up family cancer clinic in Sofia and represents the first part of a research project.

Objectives: To assess the attitude of medical professionals towards the potential opportunity for testing healthy people for genes predisposing to cancer.

Setting: The study was carried out with the participation of staff in University hospitals of Obstetrics/Gynecology and Pediatrics. Study design: the participants have been entered into the study unselectively and tested by a personal interview and a questionnaire comprising 11 items, including family and past history.

Participants: 38 women, medical professionals/doctors, biologists, psychologists, nurses, midwives, technicians (aged 25 to 73), subdivided into two groups, under 45 and older, have been studied.
Results: 11 out of 38 participants (29\%), 3 of them below 45 (27\%), 8 above 45 (73\%) refused to collaborate either directly or indirectly. Six out of the collaborating 27 participants (22\%) reported personal experience with or positive family history of cancer/breast cancer in 3 cases. Approximately $1 / 3$ of the female medical professionals, predominantly of older age, have been reluctant to discuss cancer matters personally. Strong positive correlation between educational degree and the level of knowledge about cancer and its current management have been found. Two thirds of the participants $(67 \%)$, regardless of their educational level, would have accepted pre-symptomatic breast cancer testing, if available.

Conclusions: The majority of medical professionals of all levels need more information concerning modern management of breast cancer. Most of them demonstrated a positive attitude towards testing for genes, predisposing to breast cancer and consider this approach acceptable for themselves, their families and patients.

Future Proposals: To study two more groups of non-medical healthy people of both sexes, with and without family history of cancer by using the same design. 


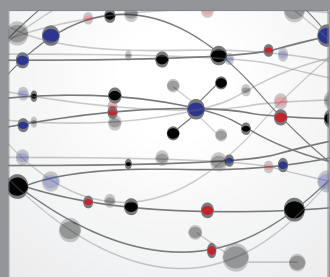

The Scientific World Journal
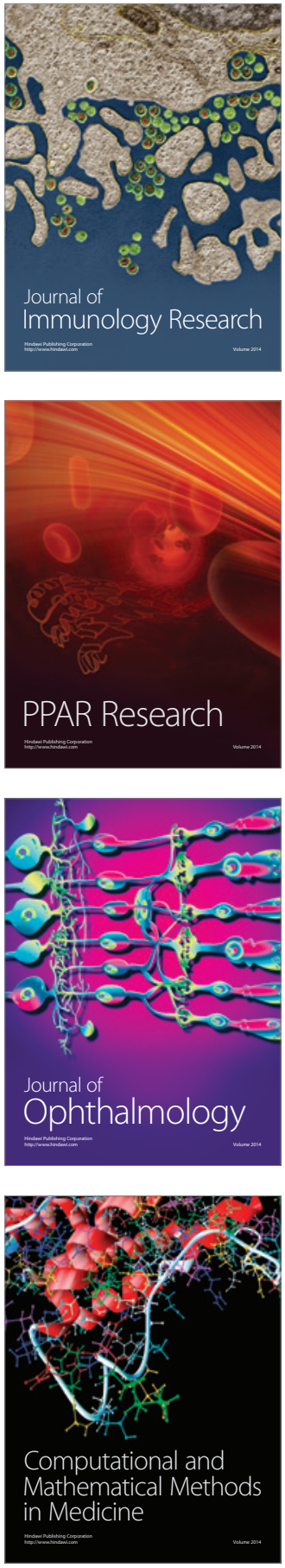

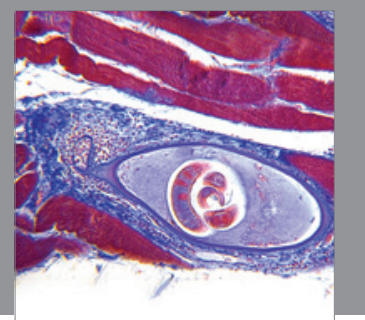

Gastroenterology

Research and Practice
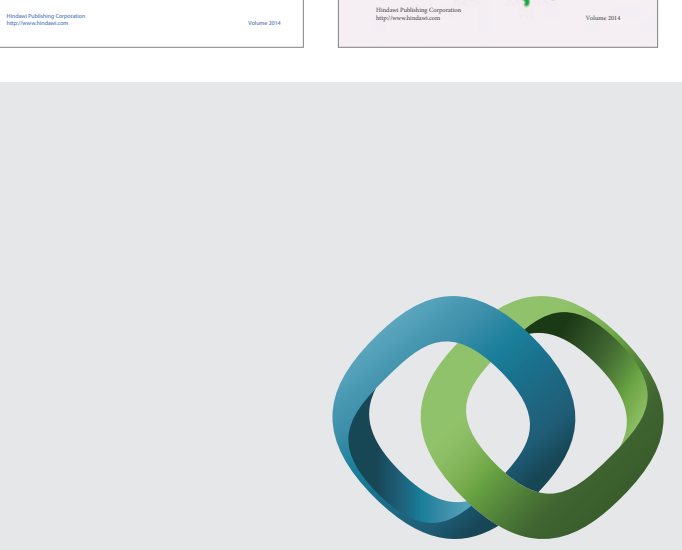

\section{Hindawi}

Submit your manuscripts at

http://www.hindawi.com
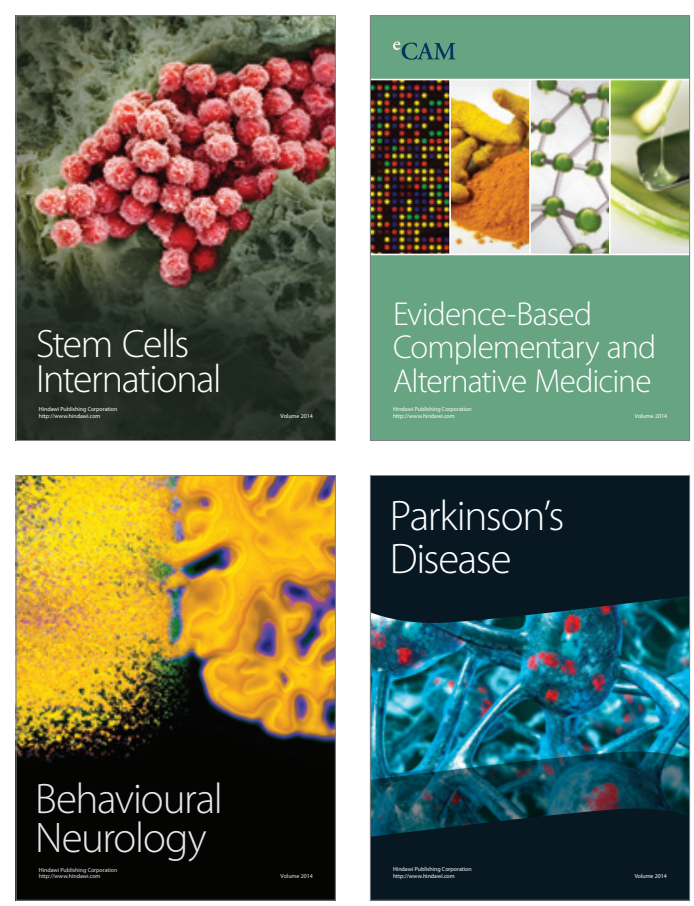

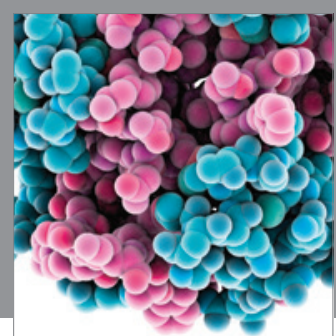

Journal of
Diabetes Research

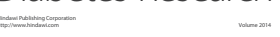

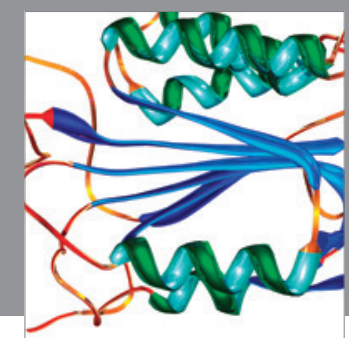

Disease Markers
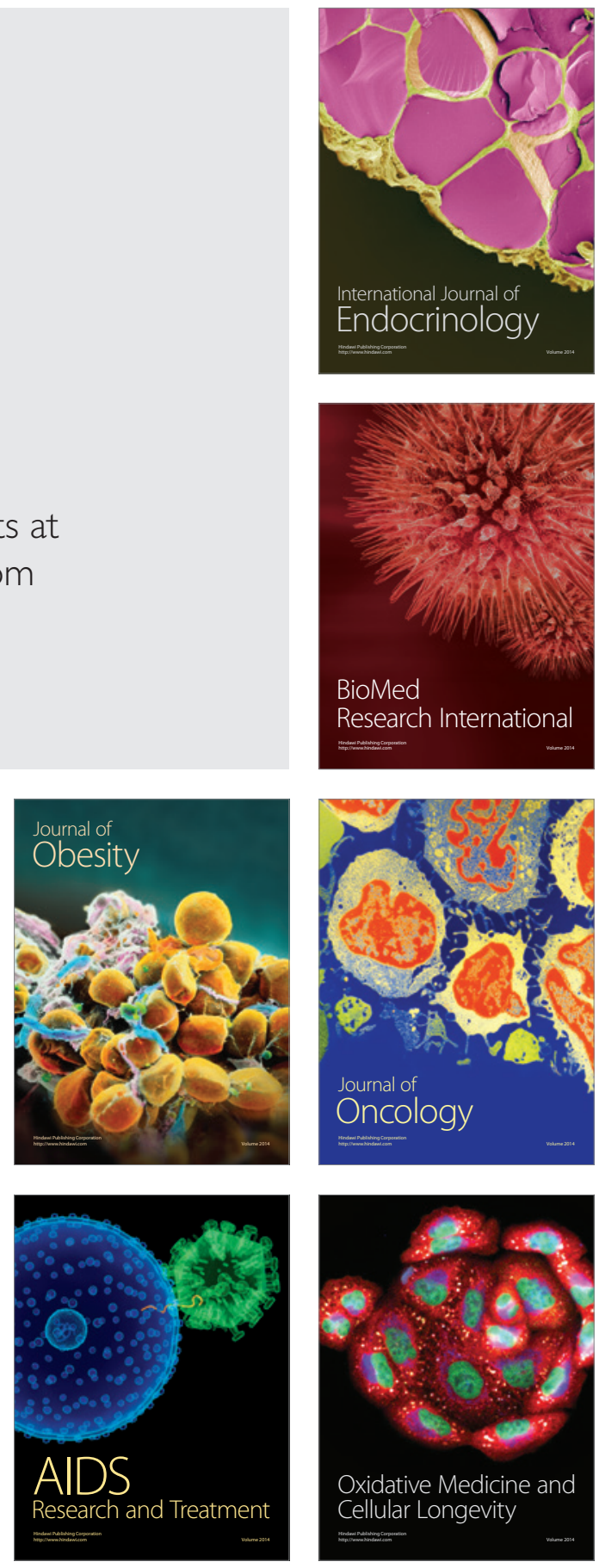